\title{
A Survey on Texture Based Weed Identification System for Precision Farming
}

\author{
Ms. J. Mohana Preethi ${ }^{1}$, Mrs. Dr. M. Sujaritha ${ }^{1}$ \\ Dept of Computer Science and Engg, Sri Krishna College of Engineering and Technology, Coimbatore, India ${ }^{1}$
}

\begin{abstract}
Weed control within crop fields is one of the main problems in organic farming. For centuries, different weed removal tools have been used to minimize weeds in the crop fields. The automation of weed detection and removal in the agricultural field is a vital task which greatly improves the cost effectiveness and efficiency of the weed removal processes. This paper compares four texture extraction and one feature selection method tailored for weed removal process. Nowadays several image processing techniques are used for the removal of weeds in crop field. Eventually it also discusses the performance of those texture extraction methods and feature selection methods concludes the challenges facing in the present day research of weed removal technique in image processing.
\end{abstract}

Keywords: chemical weeding, physical weeding, morphological operation, texture extraction, feature selection, classification.

\section{INTRODUCTION}

Sugarcane crop production is a major contributor to the and integrated weed management are required to achieve Indian economy. In order to achieve maximum yield, the both economic and environmental goals. best agricultural practices must be followed. One of the most important practice is weed management. Weeds adversely affect the sugarcane crop yield as they compete in acquiring plant nutrients and resources ${ }^{[1,2]}$. They are also responsible for harbouring various crop pests and diseases. Weeds have very fast growth rates compared to crops, and if not treated and managed, they may dominate the field. Germination of sugarcane crop completes in 2030 days. This initial germination lets us to identify the difference between the crops and weed.

The simplest weed control method is manual weed control. But the main disadvantage in this method is that the labour required for manual weeding is expensive, time consuming and difficult to organize [2]. Furthermore, several health issues involved with the manual labourers make manual weed control difficult to implement.

Advances in computational and detection capabilities have led to the implementation of automation of agricultural practices. With automation, the weed removal process is operated autonomously which reduces human intervention and optimizes the mechanical functionalities of the machine. Automated machines also offer the choice of weed removal ${ }^{[3]}$. This include

i) Chemical weeding

ii) Mechanical weeding.

\subsection{Chemical Weeding}

Typically, herbicides are applied uniformly to a whole field with no regard to the spatial variability of the weeds in the field. However, if herbicides are to be applied variably based on weed density, the amount of herbicide being used can be significantly reduced. Also manual sampling of weed is both labour and cost prohibitive in the current scenario. Thus, site-specific weed management

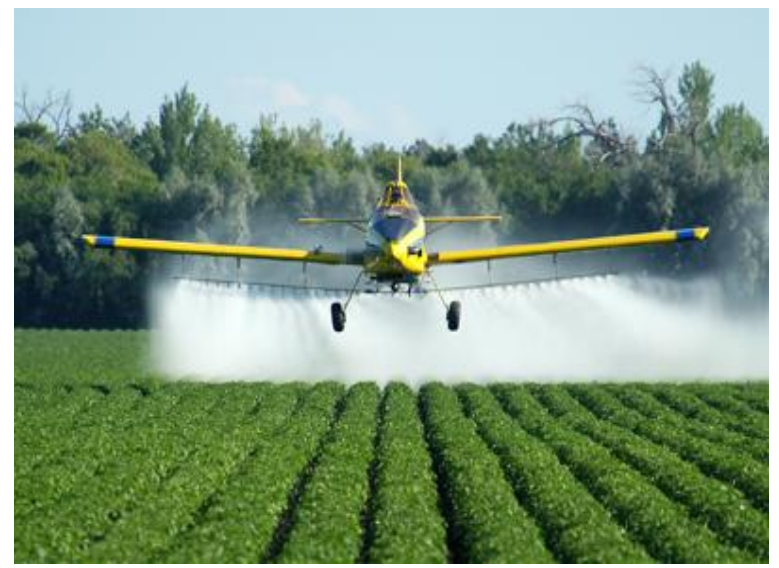

Fig1. Chemical Weeding

1.2 Mechanical weeding

Mechanical approaches use selective machines or add-on tools to perform weed control close to the crop, without damaging the crop. Manual weed control is highly accurate due to the human intelligence in identifying the weeds but it requires a lot of human labour for the mechanical effort. Mechanical weed removal using machines is fast and provides a lot of force but is highly inaccurate due to lack of intelligence. Automating the mechanical weeding process combines the advantages of manual and mechanical approaches. The proposed system has been developed to classify the sugarcane crop and common weed species in the sugarcane field and can be used to guide the chemical or mechanical weed control devices generally in any agriculture field. This paper is structured as follows. The summary of the related work of weed detection is elaborated in section II. This is followed 
by a detailed description of four texture extraction technique in section III.

Then the comparative analysis of four weed detection technique is provided in section IV. Section V concludes with suggesting the extension of proposed work.

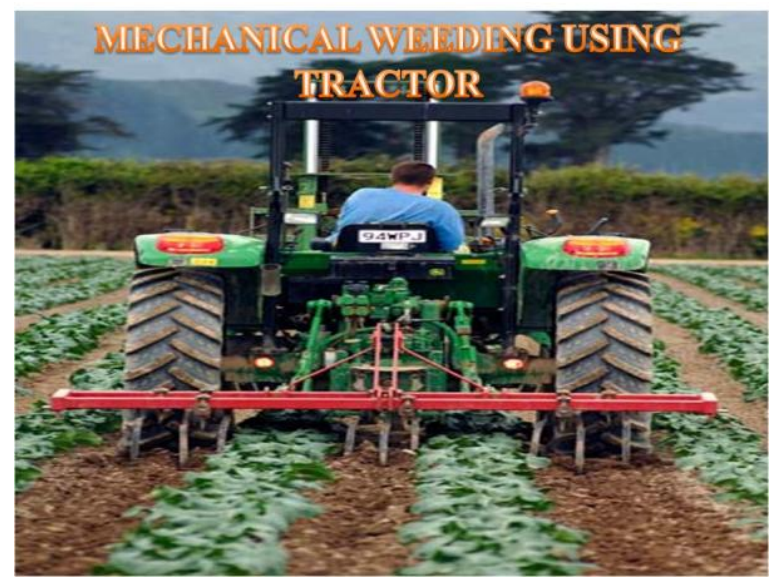

Fig2. Mechanical Weeding

\section{RELATED WORK}

Various implements have been specially designed and manufactured to control weeds in the crop fields (e.g.Ascard \& Bellinder, 1996; Bowman, 1997). During the last ten years, researches has successfully focused on harrowing, torsion and weeding with the compressed air. The possibilities for using these weeding machines vary according to crop type, crop growth stage and field- and weather conditions and depend on selectivity. This selectivity is based on differences between weed and crop plants. Weed management is the essential practice in any agricultural field. Weeds affect crop yields due to competition to acquire crops nutrients and resources (Slaughter et al.,2008; Weide et al., 2008). Weeds have very fast growth rates compared to crops, and if it not treated well, they may dominate the field. In sugarcane weeds have been estimated to cause 12 to $72 \%$ reduction in cane yield depending upon the severity of infestation. Weeds infestation in sugarcane crop is entirely different and is a specific problem when compared with any other crop. This fact can be understood by specific reasons like establishment of weeds in crop as eradication of weeds from plant crop is not possible at affordable cost, wider row spacing $(60-120 \mathrm{~cm})$, slow initial growth (30 - 45 days to complete germination and another 60-75 days for developing full canopy cover ), heavy fertilization and frequent irrigations and very little preparatory tillage in ratoon crop. All these factors are responsible for weed infestations which in turn offer a great competition for crop growth in terms of space and input. Major weed flora observed in sugarcane fields are: Sedges- Cyprus rotundus; Grasses-Cynodon dactylon, Sorghum helepense, Panicum spp, Dactylocternium aegyptium, and Broad leaves weeds - Chenapodium album, Convolvulus arvensis L., Amaranthus viridis L., Portulaca oleraceae L.,
Commelina bengalensis L. Weeds flora in sugarcane field competes for the moisture and light also eliminates about 4 times $\mathrm{N}$ and $\mathrm{P}$ and 2.5 times of $\mathrm{K}$ as compared to crop during the first 50 days period. Weeds also harbor certain diseases and pests that attack sugarcane and thus lead to indirect loss. Poor growth of cane resulting from weed infestation also affects quality. Weeds that are presents along the same row cause more harmness than those present in the inter-row spaces during early crop growth sub-periods. Thus the starting 90-120 days period of crop growth is considered as most critical period of weed competition in agriculture. Therefore, the weed management practice adopted should ensure a weed-free field for the first 3-4 months period.

\section{TEXTURE EXTRACTION}

Image analysis involves investigations of the image data for a specific application. Normally, the raw data of a set of images is analyzed to gain discernment into what is happening with the images and how they can be used to extract desired information(images). In image processing and pattern recognition and feature extraction is an important step, which is one of the special forms of dimensionality reduction. When the input data is large to be processed and suspected to be redundant then data is transformed into a decreased set of feature representations. The process of transforming the input data into the set of features is called as a feature extraction. Features often contain information relative to color, shape, texture or context according to the input.

\section{Second order Gray level matrix}

The process to generate four symmetrical co-occurrence matrix considering a $4 \times 4$ image represented with four gray-toned values from 0 to 3 . For the purpose we considered one neighboring pixel $(\mathrm{d}=1)$ along the four possible directions as $\left\{\left[\begin{array}{ll}0 & 1\end{array}\right]\right.$ for $00 ;\left[\begin{array}{ll}-1 & 1\end{array}\right]$ for $450 ;\left[\begin{array}{ll}-1 & 0\end{array}\right]$ for 900 and $[-1-1]$ for 1350$]\}$.

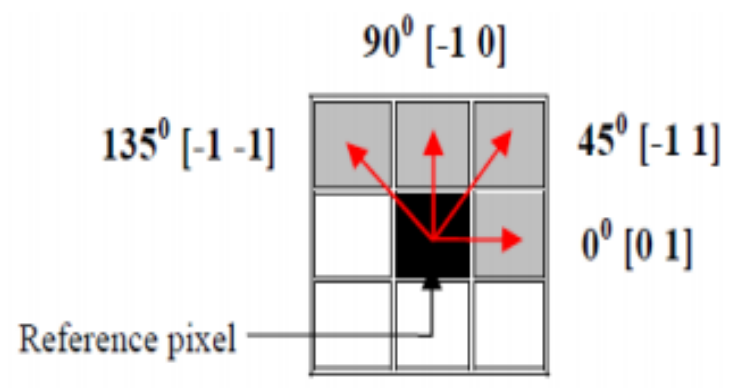

Fig3. Co-occurrence matrix directions for extracting texture features

Each element of the GLCM is the number of times that two pixels with gray tone $i$ and with $\mathrm{j}$ are neighbor in the distance $\mathrm{d}$ and direction $\theta$. For 00 co-occurrence matrix, there are 2 occurrence of the pixel intensity value 1 and pixel intensity value 3 are adjacent to each other in the input. Also, the occurrences of pixel intensity value 3 and 
pixel intensity value 1 are adjacent to each other is 2 The Gabor wavelet function is a two-dimensional times. Hence, these matrices are symmetric(identical) in nature and the co-occurring pairs obtained by choosing $\theta$ equal to $0^{\circ}$ would be similar to those obtained by choosing $\theta$ equal to $180^{\circ}$. This concept may extends to $45^{\circ}, 90^{\circ}$ and $135^{\circ}$ as well. With all these considerations, the GLCM matrix is calculated for each of the four possible angles which is shown below.

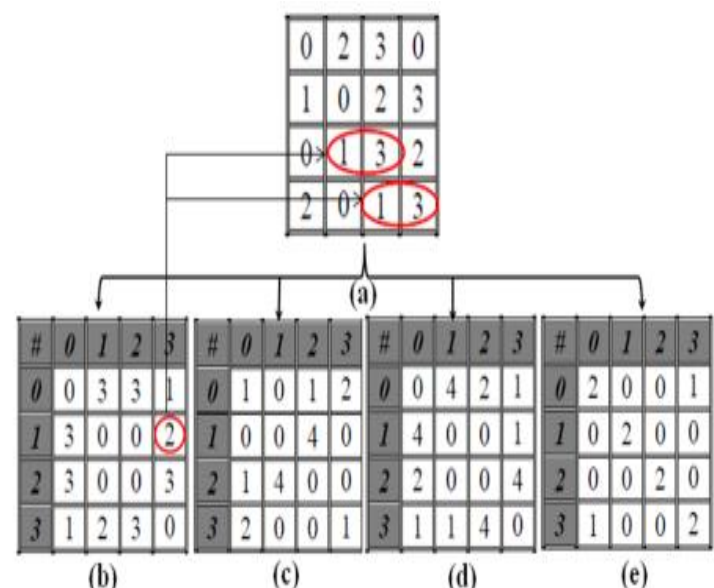

Fig4. GLCM construction based on a (a) test image along four possible directions (b) 00 (c) 450 (d) 900 and (e) 1350 with a distance $d=1$. Here \# represents the number of times.

\section{Law's texture feature}

Laws developed a texture-energy approach that measures the amount of variation within a fixed-size window. A set of twenty $5 \times 5$ convolution masks is used to compute texture energy images (TE). The masks are computed from the following vectors: L5 (Level) $=\left[\begin{array}{lllll}1 & 4 & 6 & 4 & 1\end{array}\right]$; E5 $($ Edge $)=\left[\begin{array}{lllll}-1 & -2 & 0 & 2 & 1\end{array}\right] ; \quad$ S5 $($ Spot $)=\left[\begin{array}{lllll}-1 & 0 & 2 & 0 & -1\end{array}\right] ;$

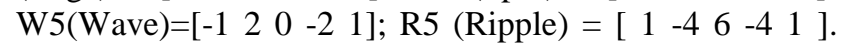
These TE images are normalized pixel-by-pixel with the L5L5T image (and then L5L5T is removed) and they are averaged corresponding to symmetrical kernels (such as R5L5 and L5R5), and taking into account that 20 out of 24 kernels (after removing L5L5) are symmetric one to each other, 14 TR images were produced ( $\mathrm{R}$ stands for 'Rotational invariance'). From each one of the 14 TR images, 5 first-order statistics (mean, standard deviation, range, skewness and kurtosis) were computed (i.e., 5 statistical features computed from 14 energy maps), giving in total 70 texture features.

\section{Gabor's wavelet}

In the research, the two dimensional ( $\mathrm{x}$ and $\mathrm{y}$ ) elementary Gabor wavelet function is used for weed and crop feature extraction ${ }^{[20]}$ and was defined as:

$$
\begin{gathered}
h(x, y)=\exp \left[-\alpha^{2 j} \frac{x^{2}+y^{2}}{2}\right] \cdot \exp \left[j \pi \alpha^{j}(x \cos \theta+y \sin \theta)\right] \\
\text { Where } \alpha=\frac{1}{\sqrt{2}}, j=0,1,2 \ldots \theta \in[0,2 \pi
\end{gathered}
$$

Gaussian envelope with standard deviation $\alpha^{-j}$ modulated by a sinusoid with frequency $\frac{\alpha^{j}}{2}$ and orientation $\theta$. The different choices of frequency level $j$ and orientation $\theta$ were used to construct a set of filters. As the frequency of the sinusoid changes, the window size changes. This filter bank was composed of spatial domain filters that are generated from the elementary Gabor wavelet function. At each frequency level in the filter bank, there was a couple of filters that corresponds to the real and imaginary parts of the complex sinusoidal in the Gabor wavelet function. The filter output at each frequency level was computed as:

$V[j]=\sqrt{\chi_{j}^{2}+\omega_{j}^{2}}$

Where $\chi_{j}$ is the mean output of the real filter mask, and $\omega_{j}$ is the mean output of the imaginary filter mask, both at frequency level $\mathrm{j}$ across multiple sample points. At every frequency level, the filter bank produced one texture feature. The filter banks are defined by the number and levels of frequencies and the filter dimension or said to be as mask size. The filter orientation was fixed at $90^{\circ}{ }^{[20]}$ Fourty sample images containing all nine weed species and sugarcane crop were randomly selected for an experiment to select these filter bank parameters.

Ten frequency levels from 0 to 9 and three mask sizes of 9 x 9 pixels, $13 \times 13$ pixels, and $17 \times 17$ pixels were investigated to measure the effect of frequency level and mask size on class separability.

\section{Proposed Rotation-invariant Wavelet features}

The wavelet features extracted from the proposed rotationinvariant texture extraction method are examined in this section for feature selection. Five levels of wavelet decomposition with $\mathrm{db} 2$ wavelet basis is performed on the input texture images and their energy features are calculated. The three sub matrices corresponding to the highest resolution were removed and not used for feature extraction. This is because for this real time data set, these sub matrices correspond to the noise (like sand, thick edges etc.) and are not valuable for classification. So, the features were calculated from 13 sub matrices.

\section{FEATURE SELECTION PROCESS}

Feature selection: A systematic effort has been taken to analyse the performance of the traditional and advanced features. Euclidean classifier is utilized for evaluating these features individually. The features with more than 65 per cent classification percentage would be considered as good features. Since single feature is used for classification in this experiment the classification performance would be less than 75 per cent. But this experiment helps to find the good features from each 
texture extraction method for this weed/crop classification application.

Table 1 shows the Correct classification percentage (CCP) obtained by various texture features. The features with CCP more than 65per cent (G9, G10, G11, T6, T8, W6, $\mathrm{W} 9, \mathrm{~W} 12$, and $\mathrm{W} 13$ ) are selected and given as input to the proposed Fuzzy Real Time Classifier (FRTC).

Table1. Correct classification percentage $(\mathrm{CCP})$ obtained by different features that are extracted through different Texture Feature extraction methods

\begin{tabular}{|c|c|c|c|c|}
\hline \multirow{3}{*}{\begin{tabular}{|l|} 
Features \\
Gabor wavelet Orientation: $90^{\circ}$
\end{tabular}} & \multicolumn{3}{|c|}{ Specification } & \multirow[b]{3}{*}{$\begin{array}{l}59.3 \\
59.7 \\
59.4 \\
58.2 \\
63.9 \\
62.3 \\
63 \\
64.1 \\
68.9 \\
69.6 \\
69.5 \\
64.7\end{array}$} \\
\hline & Name & \multicolumn{2}{|c|}{\begin{tabular}{|l|l|l} 
frequency Mask size &
\end{tabular}} & \\
\hline & $\begin{array}{l}\text { G1 } \\
\text { G2 } \\
\text { G3 } \\
\text { G4 } \\
\text { G5 } \\
\text { G6 } \\
\text { G7 } \\
\text { G8 } \\
\text { G9 } \\
\text { G10 } \\
\text { G11 } \\
\text { G12 }\end{array}$ & $\begin{array}{l}4 \\
5 \\
6 \\
7 \\
4 \\
5 \\
6 \\
7 \\
4 \\
5 \\
6 \\
7\end{array}$ & \begin{tabular}{|l}
$9 \times 9$ \\
$9 \times 9$ \\
$9 \times 9$ \\
$9 \times 9$ \\
$13 \times 13$ \\
$13 \times 13$ \\
$13 \times 13$ \\
$13 \times 13$ \\
$17 \times 17$ \\
$17 \times 17$ \\
$17 \times 17$ \\
$17 \times 17$
\end{tabular} & \\
\hline \multirow{2}{*}{$\begin{array}{l}\text { Laws Texture } \\
\text { First order statistics :mean }\end{array}$} & Name & \multicolumn{2}{|c|}{ Energy Nap } & \\
\hline & $\begin{array}{l}\text { T1 } \\
\text { T2 } \\
\text { T3 } \\
\text { T4 } \\
\text { T5 } \\
\text { T6 } \\
\text { T7 } \\
\text { T8 } \\
\text { T9 } \\
\text { T10 } \\
\text { T11 } \\
\text { T12 } \\
\text { T13 } \\
\text { T14 } \\
\end{array}$ & \multicolumn{2}{|c|}{ 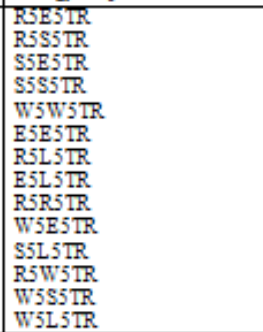 } & $\begin{array}{l}64.6 \\
63.4 \\
62.3 \\
61.7 \\
60.7 \\
69.6 \\
54.2 \\
69.6 \\
54.3 \\
53.6 \\
56.5 \\
57.3 \\
52.4 \\
57.3 \\
\end{array}$ \\
\hline $\begin{array}{l}\text { Gray level co occumence } \\
\text { matrix(GLCM) }\end{array}$ & $\begin{array}{l}\text { M11 } \\
\text { M.2 } \\
\text { M.3 } \\
\text { M.4 } \\
\text { M.5 } \\
\text { M16 } \\
\text { M:7 } \\
\text { M.8 } \\
\text { M.9 }\end{array}$ & \multicolumn{2}{|c|}{$\begin{array}{l}\text { Maximum Probability } \\
\text { Energy } \\
\text { Entropy } \\
\text { Contrast } \\
\text { Cluster Shade } \\
\text { Cluster Prominence } \\
\text { Homogeneity } \\
\text { Inverse Difference Moment } \\
\text { Correlation }\end{array}$} & $\begin{array}{l}60.1 \\
62.4 \\
64.3 \\
64.1 \\
59.3 \\
58.6 \\
62.3 \\
61.6 \\
62.4\end{array}$ \\
\hline \multirow{3}{*}{$\begin{array}{l}\text { Proposed wavelet features } \\
\text { with } \mathrm{DB} 2 \text { and energy measure }\end{array}$} & Name & Level & Feature & \\
\hline & $\begin{array}{l}\text { W1 } \\
\text { W2 } \\
\text { W3 } \\
\text { W4 } \\
\text { w5 } \\
\text { w6 } \\
\text { W7 } \\
\text { W8 } \\
\text { w9 }\end{array}$ & $\begin{array}{l}2 \\
2 \\
2 \\
3 \\
3 \\
3 \\
3 \\
4 \\
4 \\
4 \\
4\end{array}$ & $\begin{array}{l}\text { Horizontal detail } \\
\text { Vertical detail } \\
\text { Diagonal detail } \\
\text { Horizontal detail } \\
\text { Vertical detail } \\
\text { Diagonal detail } \\
\text { Horizontal detail } \\
\text { Vertical detail } \\
\text { Diagonal detail } \\
\end{array}$ & $\begin{array}{l}64.7 \\
63.9 \\
64.3 \\
63.3 \\
62.4 \\
69.6 \\
62.6 \\
61.4 \\
749 \\
\end{array}$ \\
\hline & $\begin{array}{l}\text { W10 } \\
\text { W11 } \\
\text { W12 } \\
\text { W13 } \\
\end{array}$ & \begin{tabular}{|l}
5 \\
5 \\
5 \\
5 \\
\end{tabular} & $\begin{array}{l}\text { Horizontal detail } \\
\text { Vertical detail } \\
\text { Diagonal detail } \\
\text { Approximation } \\
\end{array}$ & $\begin{array}{l}63.4 \\
62.7 \\
74.6 \\
75.3 \\
\end{array}$ \\
\hline
\end{tabular}

\section{CONCLUSION}

Weeds are undesirable plants growing within a crop and they compete for resources such as nutrients, water and light. Without weed control, crop yields is highly affected asweeds can also cause problems such as harbouring pests and causing pathogen migration, interfering with harvest operations, and increasing costs of cleaning and drying the crop produce. As recent researches have established that weeds are distributed non-uniformly across the fields, weed control based on conventional practice of spread or lined applications of herbicide is therefore undesirable, in both economic and ecological conditions. In order to implement site-specific weed management, information on weed location is required. As manual surveying is a highly labour demanding job, automatic techniques using leaftexture feature extraction and a new real time classification algorithm for determination of weeds have been proposed.

\section{REFERENCES}

[1] Slaughter DC, Giles DK, Downey D, "Autonomous robotic weed control systems: A review". Computers and Electronics in Agriculture 61(1) 2008, 63-78.

[2] Weide, R Y V D, Bleeker P O, Achten V T J M, Lotz L A P, Fogelberg F, and Melander B, "Innovation in mechanical weed control in crop rows". Weed Research 48 (3) 2008 215-224.

[3] Bakker T, "An autonomous robot for weed control - design", navigation and control. $\mathrm{PhD}$ Thesis, Wageningen University, Department of Agricultural Engineering, 2009.

[4] Franz, E, Gebhardt M R, and Unklesbay K B, "Shape description of completely visible and partially occluded leaves for identifying plants in digital images", Trans ASAE 34(2) 1991, 673-681.

[5] Woebbecke D M, Meyer G E, Von Bargen K, and Mortensen D A, "Shape features for identifying young weeds using image analysis". Trans Am. Soc. Agric. Eng 38(1) 1995 271-281.

[6] Meyer G E, Hindman T W, \& Lakshmi K, "Machine vision detection parameters for plant species identification". Bellingham, WA SPIE (1998).

[7] Tang L, Tian L F, Steward B L and Reid J F, “Texture-based weed classification using gabor wavelets and neural network for real-time selective herbicide applications". ASAE 1999

[8] Burks T F, Shearer S A, and Payne F A, "Classification of weed species using colour texture features and discriminant analysis", Trans ASAE 43(2) 2000 441-448.

[9] Cho S I, Lee D S, Jeong J Y, "Weed-plant discrimination by machine vision and artificial neural network", Biosyst Eng 83(3) ,(2002) 275-280.

[10] Vrindts E, De Baerdemeaeker J, and Ramon H , "Weed detection using canopy reflection". Precision Agriculture 3(1) 2002, 63-80.

[11] Meyer G E, Neto J C, "Verification of colour vegetation indices for automated crop imaging applications". Computers and Electronics in Agriculture, 63 (2008) 282-293.

[12] Guerrero JM, Pajares G, Montalvo M, Romeo J, Guijarro M, "Support vector machines for crop/weeds identification in maize fields" , Expert Systems with Applications 39 (12), (2012) 1114911155 .

[13] Rainville F M, Durand A, Fortin F A, Tanguy K, Maldague X, Panneton B, Simard M J, Bayesian "classification and unsupervised learning for isolating weeds in row crops", Pattern Analysis and Applications, 17, (2), 2014 401-414.

[14] Perez A J, Lopez F, Benlloch J V, \& Christensen S, "Colour and shape analysis techniques for weed detection in cereal fields", Computers and Electronics in Agriculture 25 2000, 197-212.

[15] Kataoka T, Kaneko T, Okamoto H, \&Hata S, "Crop growth estimation system using machine vision". In The 2003 IEEE/ASME international conference on advanced intelligent mechatronics, (2003).

[16] Hague T, Tillet N, \& Wheeler H, "Automated crop and weed monitoring in widely spaced cereals". Precision Agriculture, 1(1), (2006) 95-113.

[17] Romeo J, Pajares G, Montalvo M, Guerrero JM, Guijarro M, “A new Expert System for greenness identification in agricultural images", Expert Systems with Applications 40 (6), 2013, 22752286

[18] Kourosh JK \& Hamid SZ, "Rotation-Invariant Multiresolution Texture Analysis Using Radon and Wavelet Transforms", IEEE Trans. on image processing, 14 (6) 2005 783-795.

[19] Tang L, Tian L., and Steward B L, "Classification of broadleaf and grass weeds using gabor wavelets and an artificial neural network". Transactions of the ASAE 46(4) 2003, 1247-1254 
[20] Zafar N, Rehma S U, Gillani S, Asghar S, "Segmentation of Crops and Weeds Using Supervised Learning Technique in Improving Knowledge Discovery through the Integration of Data Mining Techniques" edited by Muhammad Usman, IGI-Global, 2015, 308333.

[21] RY Van Der Weide, P O Bleeker, V T J M Achten_, L A P Lotz_, F Fogelberg_ \& B Melander "Innovation in mechanical weed control in crop rows" The Authors Journal Compilation _ 2008 European Weed Research Society Weed Research, 26 July 2007.

[22] Burks, T. F. 1997. "Color image texture analysis and neural network classification of weed species", Ph.D. Thesis. Lexington Ky. University of Kentucky, Biological and Agricultural Engineering.

[23] M. Guijarro3*, G. Pajaresb, I. Riomorosc, P.J. Herrerad, X.P. Burgos-Artizzue, A. Ribeiroe," Automatic segmentation of relevant textures in agricultural images", Computers and Electronics in Agriculture, 2010 Elsevier.

[24] L. Tang, L.F. Tian, B.L. Steward and J.F. Reid, ”Texture-Based Weed Classification Using Gabor Wavelets and Neural Network for Real-time Selective Herbicide Applications".

\section{BIOGRAPHY}

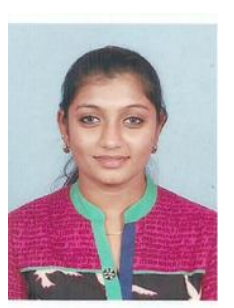

Mohana Preethi J received a BE degree in Computer Science and Engineering from Info institute of Engineering in 2015. She currently purses ME in the Department of Computer Science and Engineering at Sri Krishna College of Engineering and Technology, include image processing.

Coimbatore, India. Her research interests 